\title{
Information About Low Participation in Cancer Screening Demotivates Other People
}

Psychological Science $X X(X)$ I-3

(C) The Author(s) 2010 Reprints and permission: sagepub.com/journalsPermissions.nav DOI: $10.1177 / 0956797610373936$ http://pss.sagepub.com @SAGE

\author{
Monika Sieverding, Sarah Decker, and Friederike Zimmermann \\ University of Heidelberg
}

Received 10/28/09; Revision accepted I//8/10

Health education campaigns that aim to increase rates of attendance at preventive health screenings often present information about low participation rates. An example from the United States reads, "A new survey ... found that $89 \%$ of women still do not think or are not sure that they are at risk for infection with the virus" (Gynecologic Cancer Foundation, 2009). One from Germany states, "Only every second woman and every fifth man in Germany makes use of these cancer screening examinations" (Deutsche Krebshilfe e.V., n.d.).

Does information about low rates of participation motivate or demotivate individuals who have not yet made use of a preventive health service? Two main types of social influences on human behavior are distinguished (Deutsch \& Gerard, 1955): normative social influence (what is commonly approved) and informational social influence (what is commonly done). The latter type of social influence has recently been referred to as the "Cialdini effect" (Keizer, Lindenberg, \& Steg, 2008): "If everyone is doing it, it must be a sensible thing to do" (Cialdini, Reno, \& Kallgren, 1990, p. 1015). Norms based on what is commonly done, or descriptive norms, were first convincingly demonstrated in field studies on littering behavior, but they influence health-related behavior as well (Rivis \& Sheeran, 2003). People may infer such norms from information on the proportion of people who engage in a particular behavior (Jemmott, Ditto, \& Croyle, 1986). Buunk, van den Eijnden, and Siero (2002) found an indirect effect of (bogus) prevalence information regarding safe-sex practices among students. The effect on students' intention to use condoms was the result of a change in perceived social norms. A study of 2,426 German men detected large differences in their estimations of the prevalence of participation in cancer screening, and these estimates varied as a function of the men's own participation (Sieverding, Matterne, \& Ciccarello, 2010). Nonattenders estimated that only $28 \%$ of other men would undergo cancer screening, whereas irregular attenders estimated that $36 \%$ would, and regular attenders estimated that $45 \%$ would. Here, we report a study in which we tested the hypothesis that prevalence information about cancer screening is causally linked to intention to participate in cancer screening.

\section{Method}

Men who appeared to be ages 45 and older were approached in the pedestrian areas of two large German cities. They were briefed about screening options and detection methods in Germany, and they were then asked their age and whether they had already undergone any cancer screening. Those who were younger than 45 years and those who had previously undergone cancer screening were thanked and dismissed. Among those who had never undergone any cancer screening, 95\% agreed to participate in the study and filled out a questionnaire immediately.

These 185 participants (mean age $=53$ years) were randomly assigned to one of three groups: a low-prevalence group ( $n=65)$, a high-prevalence group $(n=65)$, or a control group $(n=55)$. The two experimental groups received different (true) German statistics (Sieverding, Matterne, Ciccarello, \& Luboldt, 2008) about 1-year or lifetime prevalence rates of cancer screening among men; the control group received no prevalence information. The low-prevalence information was worded as follows: "The most recent studies have demonstrated that only one fifth of men (only $18 \%$ !) have undergone a standard early-detection cancer examination in the last year." The high-prevalence information read, "The latest studies have demonstrated that in Germany, two thirds of all men (indeed $65 \%$ !) have already undergone a standard early-detection cancer examination." Then, variables from the theory of planned behavior (Ajzen, 1991) were assessed. We focus here on intention, which was measured with two items: "Do you intend to participate in a cancer-screening examination within the next 12 months?" (rated on a 7-point bipolar scale) and "How likely is it (from 0 to $100 \%$ ) that you will attend a cancer-screening examination within the next 12 months?"

\section{Corresponding Author:}

Monika Sieverding, Department of Psychology, University of Heidelberg, Hauptstrasse 47-5I, Heidelberg 69II7, Germany

E-mail:monika.sieverding@psychologie.uni-heidelberg.de 
As an additional, more behavioral criterion for motivation, we used active interest, which was demonstrated by a participant's choosing to leave his name and address in order to receive further information about cancer screening by mail. The threshold for providing personal data is much higher than the threshold for reporting a certain intention in an anonymous questionnaire.

\section{Results and Discussion}

Prevalence information had a significant effect on the intention to undergo a cancer screening, $F(2,182)=4.22, p<.05$, $\eta^{2}=.04$, and on the subjective probability of undergoing a cancer screening within the next year, $F(2,182)=5.23, p<$ $.01, \eta^{2}=.06$. Post hoc Scheffé tests showed that men in the low-prevalence group reported less intention to undergo a cancer screening $(M=3.5, S D=2.0)$ compared with those in the high-prevalence group $(M=4.4, S D=2.0, p<.05)$; the difference between men in the low-prevalence group and the control group $(M=4.3, S D=2.0)$ was not significant. Moreover, men in the low-prevalence group gave a much lower estimate of their probability of undergoing a cancer screening (30.8\%) than did men in the high-prevalence (46.2\%) and control (47.7\%) groups. Post hoc tests revealed that the low-prevalence group differed significantly from both the high-prevalence and the control groups.

Active interest differed significantly as a function of prevalence information, $\chi^{2}(2, N=185)=11.9, p<.01$, and had a medium effect size $(W=.25)$. In the low-prevalence group, only $18.5 \%$ of the men left their names and addresses. The corresponding percentages in the other two groups were more than double that value (see Fig. 1). A post hoc analysis revealed a significant difference in active interest between the low-prevalence and control groups; the high-prevalence group did not differ significantly from the low-prevalence group or from the control group. Thus, high-prevalence information did not increase active interest (compared with no information), but low-prevalence information decreased active interest. A cancer screening is seen as unpleasant by many people and is associated with the possibility of an emotionally draining outcome- a cancer diagnosis. A common tendency to postpone a cancer screening could be reinforced by the information that it is "normal" not to participate in cancer screening. Thus, it makes sense that the low-prevalence message showed a clear effect on cancer-screening motivation and active interest, whereas the high-prevalence message did not.

The results of this study demonstrate a clear demotivating effect of low-prevalence information on men who have never undergone a cancer screening. In designing health education campaigns, one should be very cautious in using low prevalence rates to motivate people, because this information might result in a boomerang effect: "When so few people engage in this behavior, it might not be a sensible thing to do!"

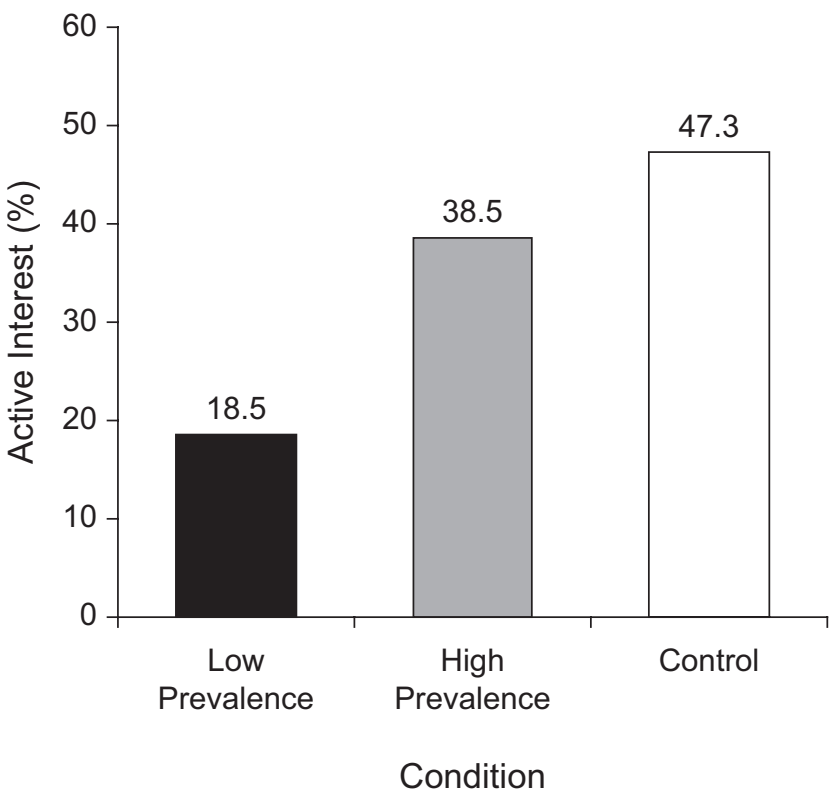

Fig. I. Percentage of men who left their names and addresses in order to receive further information about cancer screening (active interest) as a function of the prevalence information they received.

\section{Acknowledgments}

We thank Constanze Eib and Nicolai Jungk for their help in collecting data for this study. Monika Sieverding and Friederike Zimmermann were supported by a grant from the Ministry of Baden-Württemberg.

\section{Declaration of Conflicting Interests}

The authors declared that they had no conflicts of interest with respect to their authorship or the publication of this article.

\section{References}

Ajzen, I. (1991). The theory of planned behavior. Organizational Behavior and Human Decision Processes, 50, 179-211.

Buunk, B.P., van den Eijnden, R.J.J.M., \& Siero, F.W. (2002). The double-edged sword of providing information about the prevalence of safer sex. Journal of Applied Social Psychology, 32, 684-699.

Cialdini, R.B., Reno, R.R., \& Kallgren, C.A. (1990). A focus theory of normative conduct: Recycling the concept of norms to reduce littering in public places. Journal of Personality and Social Psychology, 58, 1015-1026.

Deutsch, M., \& Gerard, H.B. (1955). A study of normative and informational social influences upon individual judgment. Journal of Abnormal and Social Psychology, 51, 629-636.

Deutsche Krebshilfe e.V. (n.d.). Krebs-Früherkennung. Retrieved October 27, 2009, from http://www.krebshilfe.de/frueherkennung.html

Gynecologic Cancer Foundation. (2009). Despite widespread awareness, most women still don't feel at risk for cervical cancer. Retrieved October 27, 2009, from http://www.cervicalcancercampaign.org/ publications/20090115.html

Jemmott, J.B., Ditto, P.H., \& Croyle, R.T. (1986). Judging health status: Effects of perceived prevalence and personal relevance. Journal of Personality and Social Psychology, 50, 899-905. 
Keizer, K., Lindenberg, S., \& Steg, L. (2008). The spreading of disorder. Science, 322, 1681-1685.

Rivis, A., \& Sheeran, P. (2003). Descriptive norms as an additional predictor in the theory of planned behaviour: A meta-analysis. Current Psychology: Developmental, Learning, Personality, Social, 22, 218-233.

Sieverding, M., Matterne, U., \& Ciccarello, L. (2010). What role do social norms play in the context of men's cancer screening intention and behavior? Application of an extended theory of planned behavior. Health Psychology, 29, 72-81.

Sieverding, M., Matterne, U., Ciccarello, L., \& Luboldt, H.-J. (2008). Prostatakarzinom-Früherkennung in Deutschland: Untersuchung einer repräsentativen Bevölkerungsstichprobe [Early detection of prostate cancer in Germany: A survey with a representative sample]. Der Urologe, 47, 1233-1238. 